\title{
Nurses’ role in medical prescription: Systematic review
}

Taghrid Chaaban ${ }^{1,2^{*}}$, Mathieu Ahouah' ${ }^{1}$ Wissam Nasser ${ }^{3}$, Wafaa Hijazi ${ }^{4}$, Pierre Lombrail ${ }^{5}$, Jean-Manuel Morvillers ${ }^{1}$ and Monique Rothan-Tondeur ${ }^{1,6}$

*Correspondence: tagochaaban@hotmail.com

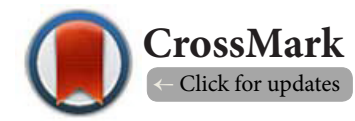

'University Paris 13, Sorbonne Paris Cite, Nursing Sciences Research chair, Laboratory Educations and Health Practices (LEPS), (EA 3412), UFR SMBH, F-93017, Bobigny.

${ }^{2}$ Islamic University of Lebanon, Faculty of Nursing Sciences, Beirut, Lebanon.

${ }^{3}$ Ministry of Public Health, Epidemiological Surveillance Unit, Beirut, Lebanon.

${ }^{4}$ Lebanese University, Faculty of public Health, Beirut, Lebanon.

${ }^{5}$ University Paris 13, Public Health, (LEPS), (EA 3412), UFR SMBH, F-93017, Bobigny, France.

${ }^{6} \mathrm{AP} \mathrm{HP}$, Nursing Sciences Research chair Paris, France.

\begin{abstract}
$\underline{\text { Aim: }}$ To identify and describe the role of non-prescribing nurses in medical prescription, through a critical synthesis of all the studies published worldwide answering this question.

Background: Medical prescription is a prerogative of the physician. Yet, the final decision for prescribing is most often the conjunction of different factors and actors. What could be the role of non-prescribing nurses in medical prescription?

Design: A systematic literature review.

Methods: A literature search of the databases, the Ovid MEDLINE database, PubMed, Web of Science, Cochrane, and Cumulative Index to Nursing and Allied Health Literature (CINAHL), was done to identify studies that describe the nurse's role in medical prescription up to May 2017. A quality assessment of relevant studies was performed.
\end{abstract}

Results: Four studies were included in this review. The overall methodological quality of the studies was intermediate (score: 8.5 of 12). Analyses of the included articles show the nurses have an essential role in the administration of medications and in the follow-up of the drug consequences. In addition, nurses tend to share the decision regarding prescribing with the doctors through an inter-professional collaborative approach. Nurses do not have sufficient knowledge about pharmacology and drug management.

Conclusions: Our systematic review emphasizes the importance of multidisciplinary collaboration between nurses and other health professionals in acute care settings. The strong involvement of nurses could provide a dialogue to strengthen best practice. Improving the nurses' knowledge and their skills are likely to enhance the optimization of treatment.

Relevance to Clinical Practice: The current literature suggests a refinement of pharmacological knowledge among nurses and effective nurse-doctor interactions to guide the best medical prescribing.

Keywords: Nurse, Physician, Medical prescription, Collaboration, Theoretical skills, Medication errors

\section{Introduction}

The nursing profession has evolved enormously since the days of Florence Nightingale, a pioneer of modern nursing. The personnel of this profession have not ceased to seek their place in the medical field. Nurses are given additional respon- sibilities and drug-related activities such as prescribing certain products and renewing treatments [1]. In most countries, the medication use process is carried out by different professionals, in such a way prescription is a medical act, dispensing is a pharmaceutical act and administration is a nursing act. As

(ㄷ) 2018 Chaaban et al; licensee Herbert Publications Ltd. This is an Open Access article distributed under the terms of Creative Commons Attribution License (http://creativecommons.org/licenses/by/3.0). This permits unrestricted use, distribution, and reproduction in any medium, provided the original work is properly cited. 
to their role in medical prescription, nurses work in relation with other health professionals. The literature has shown the active involvement of nurses in the prescription of medicines to help patients access and maintain optimal therapy [2-4].

Nurses, who are more often present with the patients than the attending physicians, provide adequate supervision in quality care, and call upon physicians when they deem it necessary. Thus, as responsible and competent professionals, nurses can exchange their observations and assessments with doctors. In fact, the interaction between the nurse and the physician allows the knowledge and skills of both professions to influence patient care in synergy [5]. Indeed, a competent nurse has a role in diagnosis [6] and proposes appropriate treatment [7]. In addition, the nurse participates in the follow-up of the treatment. This step requires, in some cases, monitoring of the clinical and biological examinations necessary for the detection of the expected adverse effects [8].

In many countries, especially in France, medication prescription is a prerogative of the doctor. However, this act is not done unilaterally by doctors, but it is most often the conjunction of different factors and actors interacting with the final decision that is the sole responsibility of the legal actor. Physicians' decision-making in medical prescribing is influenced not only by their own expertise and beliefs, but also by nurses $[4,9]$. From this perspective, a systematic review of the literature for the role of nurses in medical prescription and their influence on the physicians' decision appears necessary.

\section{Aim of the study}

The aim of this systematic review is to identify and describe the role of non-prescribing nurses in medical prescription, through a critical synthesis of all studies published worldwide answering this question.

\section{Methods}

A systematic search of the published literature was carried out with an exceptional focus on articles published in peerreviewed journals up to May 2017. The search was conducted with no language restrictions and without any limitation on seniority.

\section{Overall approach}

The Ovid MEDLINE database, PubMed, Web of Science, Cochrane, and Cumulative Index to Nursing and Allied Health Literature (CINAHL) were reviewed. In addition, the Google Scholar search engine (http://scholar.google.ca/intl/en/scholar/ about.html) was searched. A web-based search was conducted in a structured and documented manner.

\section{Literature search strategy}

The databases were searched for a specific keywords combined using the Boolean Operators 'OR' and 'AND'. The equation ((( (nurse) OR practitioner nurse) OR registered nurse) OR AND nurse's role) AND medical prescription), was used to search Pub-
Med, Medline and CINAHL. Meanwhile, the Cochrane Bank was searched using the following equation of keywords: «nurse» AND «medical prescription» OR « medication prescribing ». See Supplementary Table S1.

All studies establishing a systematic methodology and giving rise to a production of new knowledge of the role of the nurse in medical prescription was retained in the first analysis. Non-methodological literature, including "grey literature" was excluded from our systematic selection search. Articles with relating topics on prescribing nurses and those in which the nurse's place in the medical prescription was not clearly presented were excluded.

The obtained duplicates from the various search engines were eliminated. The selection process of the articles identified through keywords search involved two essential steps: A first screening of the articles was based on the relevance of the title. The second identification was carried out on the summary of each bibliographic reference retained by the literature search in order to eliminate publications not of sufficient interest.

\section{Quality appraisal}

The methodological quality of the studies included in this review was evaluated according to a set of 12 criteria based on previous systematic reviews in the healthcare field [10] See Supplementary Table S2. These criteria are designed to evaluate reliability, internal validity (ability to provide valid information on the objectives studied under the study conditions) and the external validity of its results (capacity to be generalized). Scores were assigned as 1 if a criterion was met, 0 if not met, and 0.5 if partially met. The mean score of all studies was taken as the final. As such, the quality of each study was classified based on a calculated score in one of the three categories. A study with a score of 10 or more is considered of high quality. It is of average quality if the score is between seven and nine and of low quality if it scores fewer than seven [10].

\section{Data analysis}

The analysis of each document was carried out independently by two reviewers (double-blind reading). The analysis process involves assessing the novelty of the included studies, their scientific value and their methodological quality. Disagreements were resolved by discussion and consent with a third reviewer.

\section{Results}

A total of 1541 search items were first identified from the five electronic databases. After considering search limitations and exclusion criteria, 605 documents were retained from the first screening by which 424 were excluded based on their title, 122 on their abstract and 51 were identified as relevant according to their title and abstract. Four documents were included after the full text was read (Figure 1). The methodological quality score of the four selected articles varied from 


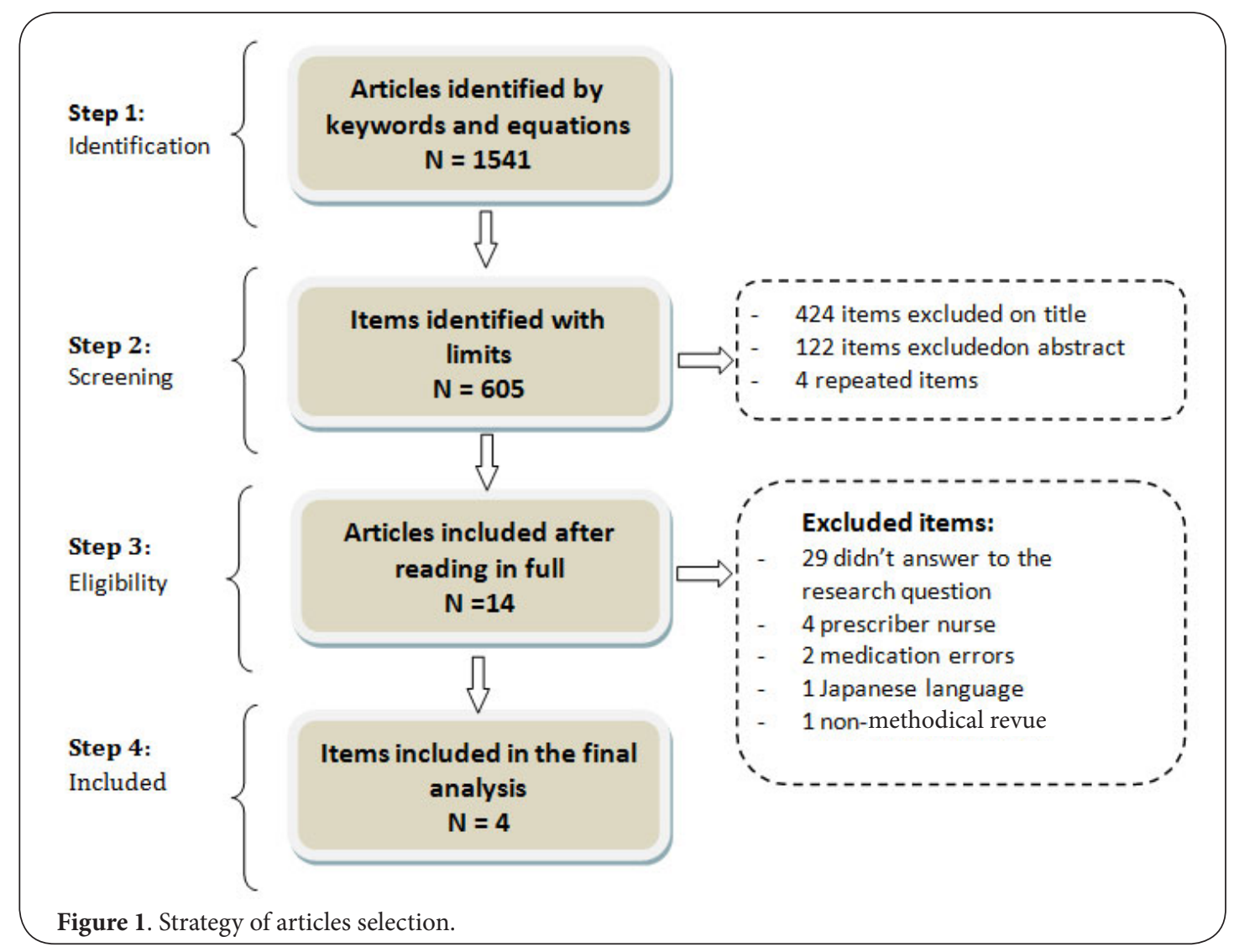

7.5 to 11.5 points out of 12 , with an overall mean score of 8.5. The characteristics of the included studies in this systematic review and their quality scores are presented in Table 1.

In this review, a total of four studies were retained from the systematic search. The participants included in these studies were hospital or health system board employees. An exploratory quantitative study by Manias et al. [11] was conducted in a public hospital in Australia with 12 graduate nurses. The average age of participants was 26 years. The nurses in this study worked in the medical and surgical departments. The goal was to examine how graduate nurses communicated with other health professionals about their medication management activities in the acute care context. Nurses in this study communicated informally with physicians when reasons for prescribing certain medications required clarification in light of the patient's medical condition. Nurses also communicated with the doctors to exchange information about the patient's health status in the event of allergies or reactions to prescribed medications. They also contact doctors to request other analgesics in case of persistent pain, and sometimes to adjust insulin doses according to glucose levels. In addition, nurses were observed to reserve the use of antihypertensive drugs in patients with unstable pulse and blood pressure and to convey this information to physicians. In this study, the nurses failed to actively seek information about medications from the physicians because they were not readily available on call and did not have an extensive knowledge about the pharmacological characteristics of medications.

Another quantitative study by Lewis \& Tully [12] studied the impact of multidisciplinary team interaction on prescribing decisions of 48 physicians from four UK hospitals, especially their discomfort when prescribing. Three main themes emerged from the analysis: prescription responsibility, pressure to prescribe and prescribe to facilitate the work of the nursing team. During interviews, physicians of all grades reported 193 incidents of uncomfortable prescription decisions related to pressure to prescribe from nurses in their early careers. Junior physicians discussed the pressure they felt from nurses to prescribe sedatives as it was easier for them to prescribe than to decline nurses' requests. In addition, the doctors in this study indicated that they had signed prescriptions that they had not prescribed and drugs that had already been administered.

The influence of nurses' activities on medical prescription and the use of medicines were examined by Jutel \& Menkes [13]. A total of 100 senior nurses employed by governmentfunded health boards in two distinct regions of New Zealand were web-surveyed. About $80 \%$ of the nurses who participated in this study reported that they recommended treatments or medication choices to prescribing physicians. Another $80 \%$ 
Chaaban et al. Journal of Nursing 2018,

Table 1. Description of included studies and results.

\begin{tabular}{|c|c|c|c|c|}
\hline Study & Objective & Design and population & Main Findings & Quality Score \\
\hline $\begin{array}{l}\text { Manias, Atiken\& Dunning; } \\
2005 \\
\text { Graduate nurses' } \\
\text { communication with health } \\
\text { professionals when managing } \\
\text { patients' medications }\end{array}$ & $\begin{array}{l}\text { To investigate how } \\
\text { nurses communicated } \\
\text { with other medical } \\
\text { professionals about their } \\
\text { medication management } \\
\text { activities in the acute } \\
\text { care settings }\end{array}$ & $\begin{array}{l}\text { Participant observation } \\
\text { and semi-structured } \\
\text { interviews for } 12 \text { graduate } \\
\text { nurses with university de- } \\
\text { grees employed in a met- } \\
\text { ropolitan public hospital, } \\
\text { in Melbourne, Australia }\end{array}$ & $\begin{array}{l}\text { Nurses communicated informal- } \\
\text { ly with physicians when reasons } \\
\text { for prescribing certain medica- } \\
\text { tions required clarification in } \\
\text { light of the patient's medical } \\
\text { condition. } \\
\text { Nurses were observed to reserve } \\
\text { the use of antihypertensive } \\
\text { drugs in patients with unstable } \\
\text { pulse and blood pressure and } \\
\text { to convey this information to } \\
\text { physicians. }\end{array}$ & 10 \\
\hline $\begin{array}{l}\text { Lewis \& Tully; } 2009 \\
\text { Uncomfortable prescribing } \\
\text { decisions in hospitals: the } \\
\text { impact of teamwork }\end{array}$ & $\begin{array}{l}\text { To examine the effect } \\
\text { that interdisciplinary } \\
\text { team collaboration had } \\
\text { upon United Kingdom } \\
\text { hospital physicians' } \\
\text { prescribing decisions }\end{array}$ & $\begin{array}{l}\text { Critical incident technique } \\
\text { and in-depth interviews } \\
\text { for } 48 \text { doctors of varying } \\
\text { grades from four United } \\
\text { Kingdom hospitals }\end{array}$ & $\begin{array}{l}\text { Physicians of all grades reported } \\
\text { several incidents of uncomfort- } \\
\text { able prescription decisions relat- } \\
\text { ed to pressure to prescribe from } \\
\text { nurses in their early careers. } \\
\text { Junior physicians discussed the } \\
\text { pressure they felt from nurses } \\
\text { to prescribe sedatives as it was } \\
\text { easier for them to prescribe than } \\
\text { to decline nurses' requests. } \\
\text { Doctors reported that they } \\
\text { became more likely to resist the } \\
\text { pressure that nurses exerted } \\
\text { on them to prescribe once they } \\
\text { became registrars. }\end{array}$ & 11.5 \\
\hline $\begin{array}{l}\text { Jutel\&Menkes; } 2010 \\
\text { Nurses' reported influence on } \\
\text { the prescription and use of } \\
\text { medication }\end{array}$ & $\begin{array}{l}\text { To report the set of } \\
\text { activities senior nurses } \\
\text { undertake which may in- } \\
\text { fluence the prescription } \\
\text { and use of medicines }\end{array}$ & $\begin{array}{l}\text { Parallel web- and paper- } \\
\text { based surveys of } 100 \\
\text { senior registered nurses } \\
\text { employed by government- } \\
\text { funded health boards in } \\
\text { two distinct New Zealand } \\
\text { regions }\end{array}$ & $\begin{array}{l}79 \%(74 / 94) \text { recommended treat- } \\
\text { ments or medication choices to } \\
\text { prescribing physicians; } \\
79 \% \text { (74/95) provided counsel- } \\
\text { ing to patients about over-the- } \\
\text { counter drugs; } \\
77 \% \text { (71/92) participated in } \\
\text { the drafting and development } \\
\text { of guidelines that included the } \\
\text { use of drugs, checking charts } \\
\text { and drug protocols, or discuss- } \\
\text { ing medications required for } \\
\text { discharge. } \\
\text { 9\% (8/92) used generic names } \\
\text { with professionals and both } \\
\text { generic and commercial names } \\
\text { with patients. }\end{array}$ & 7.5 \\
\hline
\end{tabular}


Continuation of Table 1.

\begin{tabular}{|c|c|c|c|c|}
\hline $\begin{array}{l}\text { Edwards; } 2011 \\
\text { Covering more territory to } \\
\text { fight resistance: considering } \\
\text { nurses' role in antimicrobial } \\
\text { stewardship }\end{array}$ & $\begin{array}{l}\text { To examine the extent } \\
\text { of nurses' contribution } \\
\text { to the antimicrobial } \\
\text { management within an } \\
\text { in-patient health context }\end{array}$ & $\begin{array}{l}\text { Expert opinion in the } \\
\text { United Kingdom }\end{array}$ & $\begin{array}{l}\text { Nurses can influence the physi- } \\
\text { cians' prescribing decisions by } \\
\text { encouraging drug compliance, } \\
\text { monitoring prescription deci- } \\
\text { sions and reducing prescrib- } \\
\text { ing errors (Castledine, 2006; } \\
\text { Jutel\&Menkes, 2010). } \\
\text { Nurses' introduction of non- } \\
\text { pharmacological approaches } \\
\text { and patient education to reduce } \\
\text { pain has consequently decreased } \\
\text { patients' dependence on drugs } \\
\text { (Wells-Federman et al, 2002). } \\
\text { Nurses may feel demoralized to } \\
\text { participate in antimicrobial man- } \\
\text { agement programs due to lack } \\
\text { of knowledge, which is closely } \\
\text { related to construct of power, es- } \\
\text { pecially within acute care context } \\
\text { (Hindess, 1996). } \\
\text { Prescribers may be reluctant } \\
\text { to challenge the decisions and } \\
\text { instructions of more senior } \\
\text { colleagues, which refer to the } \\
\text { "prescribing etiquette" (Lewis \& } \\
\text { Tully, 2009). }\end{array}$ & 5 \\
\hline
\end{tabular}

of nurses provided counseling to patients about over-thecounter drugs. In addition, $77 \%$ of the nurses participated in the drafting and development of guidelines that included the use of drugs, checking charts and drug protocols, or discussing medications required for discharge. Very few nurses (9\%) mentioned that they used generic names with professionals and generic and commercial names with patients.

The last article by Edwards et al. [14] summarizes the findings from different published studies to explore the nurse's place in antimicrobials management in acute care settings. The authors report that nurses can influence the decision-making process of physicians and other prescribers by encouraging drug compliance, monitoring prescribing decisions and reducing prescribing errors $[13,15]$. In this article, Wells-Federman et al. [16] also reported that the nurse's introduction of nonpharmacological approaches and patient education to reduce pain has decreased patients' dependence on drugs. However, nurses may feel demoralized to participate in antimicrobial management programs due to lack of knowledge, which is closely related to the construct of power, especially within the acute care context [17].

\section{Conceptualization of results}

The findings of the four different included articles not only can be synthesized quantitatively, but also in qualitative terms by which these results can be conceptualized into three themes.
The first theme reflects the nursing role in "application of medical prescription". The second and third themes, named "collaborative approach" and "nurse's knowledge", respectively, provide an overview to the physician-nurse interaction and to the role of nurse's knowledge in the prescription decision.

\section{Application of medical prescription}

The essential nursing role is a part of medication administration, monitoring its effects, and providing patient advice on medications $[13,14]$. In addition, the nurse is involved in drafting and development of policies and guidelines for the use of drugs [13].

\section{Collaborative approach}

The nurse shares the medical-prescribing decision with the doctor; she retains the medication in certain situations and recommends treatments to prescribing doctors [13]. Thus, the nurse can influence decision-making by prescribers through encouraging drug compliance, monitoring prescription decisions and reducing prescribing errors $[13,15]$. In fact, the participation of nurses in antimicrobial management activities could provide an opportunity to discuss antimicrobial treatment and duration with the attending physicians and pharmacists. Indeed, direct communication among health professionals, including nurses, about the use of medicines would promote best practice; thereby reducing patient's 
Chaaban et al. Journal of Nursing 2018,

morbidity and its costs, as well as reducing the length of hospital stay [14].

\section{Nurse's knowledge}

Nurses have failed to actively seek information about medications from the physicians, and they did not have a sufficient knowledge about the pharmacological characteristics of these medications [11]. Their lack of knowledge on the antimicrobial drug management precludes them from the participation in such programs [14]. Thus, the lack of theoretical skills for the nurses can be a contextual challenge in multidisciplinary drug management. Medical prescription is therefore a tri-factorial process (Figure 2). Indeed, the three different themes identified in our systematic review, particularly the inter-professional collaboration, could provide a dialogue link between the prescribing physician and the nurse to guide the best medical practice. Still, better medical prescribing requires an evaluation of medications' policies and guidelines on the one hand, and a refinement of pharmacological knowledge among nurses on the other hand.

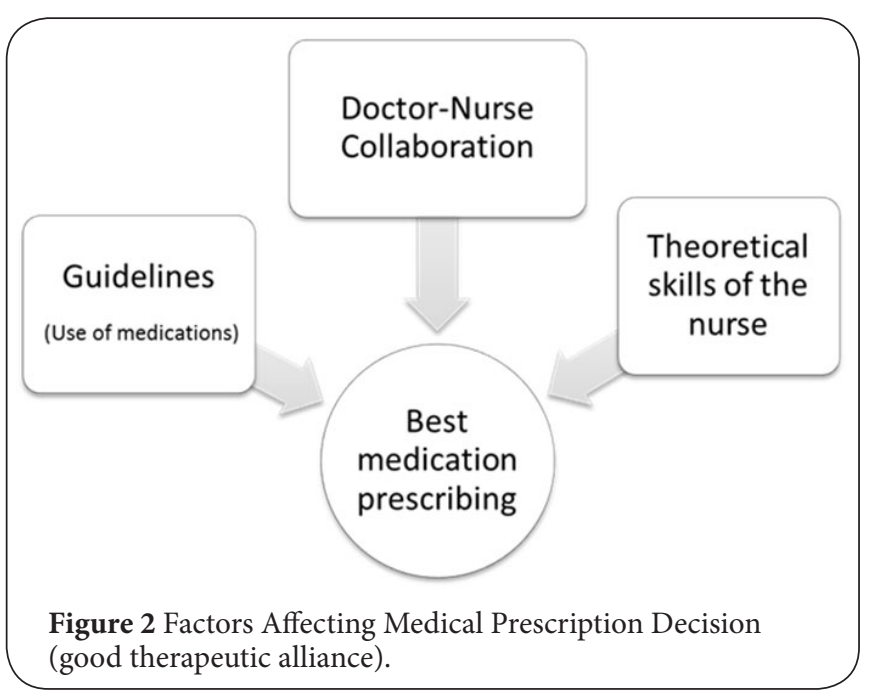

\section{Discussion}

Nurses play a key role in establishing collaboration between medical professions that contributes to multidisciplinary drug management in health care contexts and enhanced therapeutic efficiency $[14,18]$. Our research aims to understand the place of the nurse in medical prescription.

The findings from the four articles included in this systematic review have clearly cited the involvement of nurses in the decision-making process for drug prescribing. The results of the studies by Manias et al. [11] and Jutel \& Menkes [13] are confirmed in an article by Castledine [15] who demonstrated that nurses support physicians in prescribing medications and often communicate with them in cases where the certain prescriptions are not clear. In addition, nurses have a central role in drug monitoring and reducing prescribing errors. Indeed, the nurse supports the doctor in the prescription by detecting and preventing the medications errors [19]. In other terms, the nurses have a key role in effective drug management, given their proximity to the patient and their collaborative relationship with the physician [20].

Our review highlights the importance of the nurses' level of knowledge on their ability to participate in the medical prescribing decision. This comes in agreement with the results from the study by Lim et al. [21] who described the importance of knowledge among nurses so that they could share the medication decision with prescribers. It is worth to note that one study by Lim and his colleagues [22] has showed that physicians rely on nurses' assessment and information in drug prescribing. This same study shows that the inexperience of the nurse and the lack of training on the proper use of treatment medications are factors preventing optimal drug prescription. According to Edwards and his colleagues [14], nurses do not have sufficient knowledge about pharmacology and drug management. This confirms the need for more training of nursing staff in order to prevent drug consequences and prescribing errors [21]. Competent nurses should regularly review medical prescriptions and contact prescribers to eliminate unnecessary prescriptions and reduce medication errors. Indeed, increasing the nurses' level of knowledge through promoting proper training has resulted in improved prescribing [23] and in adoption of better treatment decisions [7].

It is important to emphasize that the application of prescription remains the paramount nursing role. So, the nurses are focused on medication administration, medication follow-up and therapeutic education. This comes in agreement with the results from the studies by Olsson et al. [23] and Mahlknecht et al. [8] who demonstrated that nurses conduct monitoring of the residents' clinical condition and documentation of suspect drug-related problems. Furthermore, the nurses are in a key position to collaborate with other health care professionals and contribute to multidisciplinary drug management, including the writing and development of policies and guidelines for the use of medicines.

\section{Limitations}

This systematic review has several limitations. Only very few studies on the role of nurses in medical prescription has been published. Indeed, studies on the prescribing nurses are numerous; however, none were included in our review. The possibility of publication bias cannot be ruled out, as not all research on the role of nurses in medical prescription is necessarily published, especially when results are unfavorable.

\section{Conclusion}

The final decision in drug prescription rests with the doctor, and is influenced by the nurse's attitude. Effective collaboration between nurses and physicians, particularly in 
acute care contexts, should be strengthened and always be maintained. This can be achieved through improved nurses' knowledge and nursing skills which are in turn necessary to the optimization of treatment. A very few evidence for the place of nurses in medical prescription was signed. More future research is deemed necessary to identify the nursing role in such prescription.

\section{Additional file}

\section{Supplementary Table S1}

Supplementary Table S2

\section{Competing interests}

The authors declare that they have no competing interests.

\section{Authors' contributions}

\begin{tabular}{|l|c|c|c|c|c|c|c|}
\hline Authors' contributions & TC & MA & WN & WH & PL & JM & MR \\
\hline Research concept and design & $\checkmark$ & $\checkmark$ & -- & -- & -- & $\checkmark$ & $\checkmark$ \\
\hline Collection and/or assembly of data & $\checkmark$ & -- & -- & $\checkmark$ & -- & -- & -- \\
\hline Data analysis and interpretation & $\checkmark$ & -- & $\checkmark$ & $\checkmark$ & -- & -- & $\checkmark$ \\
\hline Writing the article & $\checkmark$ & -- & $\checkmark$ & -- & -- & -- & -- \\
\hline Critical revision of the article & -- & $\checkmark$ & -- & -- & $\checkmark$ & $\checkmark$ & $\checkmark$ \\
\hline Final approval of article & -- & -- & -- & -- & -- & -- & $\checkmark$ \\
\hline Statistical analysis & $\checkmark$ & -- & $\checkmark$ & -- & -- & -- & -- \\
\hline
\end{tabular}

\section{Acknowledgement}

We would like to acknowledge the support of Steering Committee: CARTIER T., LE GONIDEC P., ZAMPONI DB., BENDELAC H., TRIBALAT R., BERTIN-HUGAULT F., ARMAINGAUD D. This research received funding from the Alere Society, Réunica Ag2R, and FondationCaissed'Epargne.

Publication history

Editor: Pamela gail Hawranik, Athabasca Universitya, Canada. Received: 03-Oct-2017 Final Revised: 23-Nov-2017

Accepted: 31-Dec-2017 Published: 12-Jan-2018

\section{References}

1. Le Boeuf D. [Nurses and medication, an expanding role]. Soins. 2014; 28-30. | PubMed

2. Manojlovich M. Power and empowerment in nursing: looking backward to inform the future. Online J Issues Nurs. 2007; 12:2. | PubMed

3. Courtenay M. Nurse prescribing, policy, practice and evidence base. $\mathrm{Br} J$ Community Nurs. 2008; 13:563-6. | Article | PubMed

4. Fleming A, Bradley C, Cullinan S and Byrne S. Antibiotic prescribing in long-term care facilities: a qualitative, multidisciplinary investigation. BMJ Open. 2014; 4:e006442. | Article | PubMed Abstract | PubMed FullText

5. Nelson GA, King ML and Brodine S. Nurse-physician collaboration on medical-surgical units. Medsurg Nurs. 2008; 17:35-40. | PubMed

6. Hornor G. Genitourinary assessment: an integral part of a complete physical examination. J Pediatr Health Care. 2007; 21:162-70. | Article | PubMed

7. Muhrer JC. The importance of the history and physical in diagnosis. Nurse Pract. 2014; 39:30-5; quiz 36. | Article | PubMed

8. Mahlknecht A, Nestler N, Bauer U, Schussler N, Schuler J, Scharer S, Becker R, Waltering I, Hempel G, Schwalbe O, Flamm M and Osterbrink $J$. Effect of training and structured medication review on medication appropriateness in nursing home residents and on cooperation between health care professionals: the InTherAKT study protocol. BMC Geriatr. 2017; 17:24. | Article | PubMed Abstract | PubMed FullText

9. Crnich CJ, Jump R, Trautner B, Sloane PD and Mody L. Optimizing Antibiotic Stewardship in Nursing Homes: A Narrative Review and Recommendations for Improvement. Drugs Aging. 2015; 32:699-716. | Article | PubMed Abstract | PubMed FullText Harden A, Brunton G, Fletcher $A$ and Oakley $A$. Teenage pregnancy and social disadvantage: systematic review integrating controlled trials and qualitative studies. BMJ. 2009; 339:b4254. | Article | PubMed Abstract | PubMed FullText

10. Manias E, Aitken R and Dunning T. Graduate nurses' communication with health professionals when managing patients' medications. J Clin Nurs. 2005; 14:354-62. | Article | PubMed

11. Lewis PJ and Tully MP. Uncomfortable prescribing decisions in hospitals: the impact of teamwork. J R Soc Med. 2009; 102:481-8. | Article | PubMed Abstract | PubMed FullText

12. Jutel A and Menkes DB. Nurses' reported influence on the prescription and use of medication. Int Nurs Rev. 2010; 57:92-7.

13. Edwards R, Drumright L, Kiernan $M$ and Holmes A. Covering more Territory to Fight Resistance: Considering Nurses' Role in Antimicrobial Stewardship. J Infect Prev. 2011; 12:6-10. | Article | PubMed Abstract | PubMed FullText

14. Castleldine G. Prescribing is not the only issue for nurses and drugs. $\mathrm{Br} \mathrm{J}$ Nurs. 2006; 15:836-7.

15. Wells-Federman C, Arnstein P and Caudill M. Nurse-led pain management program: effect on self-efficacy, pain intensity, painrelated disability, and depressive symptoms in chronic pain patients. Pain Manag Nurs. 2002; 3:131-40. | Article | PubMed

16. Hindess B. Discourses of Power: from Hobbes to Foucault. Blackwell Publishers; 1996.

17. Olans RN, Olans RD and DeMaria A, Jr. The Critical Role of the Staff Nurse in Antimicrobial Stewardship--Unrecognized, but Already There Clin Infect Dis. 2016; 62:84-9. I Article I PubMed

18. Guy J, Persaud J, Davies E and Harvey D. Drug errors: what role do nurses and pharmacists have in minimizing the risk? J Child Health Care. 2003; 7:277-90. | Article | PubMed

19. Howland RH. Effective medication management. J Psychosoc Nurs Ment Health Serv. 2012; 50:13-5. | Article | PubMed

20. Lim LM, Chiu LH, Dohrmann J and Tan KL. Registered nurses' medication management of the elderly in aged care facilities. Int Nurs Rev. 2010; 57:98-106. | Article | PubMed

21. Lim CJ, Kwong MW, Stuart RL, Buising KL, Friedman ND, Bennett NJ, Cheng AC, Peleg AY, Marshall C and Kong DC. Antibiotic prescribing practice in residential aged care facilities--health care providers' perspectives. Med J Aust. 2014; 201:98-102. | Article | PubMed

22. Loganathan $M$, Singh S, Franklin BD, Bottle A and Majeed A. Interventions to optimise prescribing in care homes: systematic review. Age Ageing. 2011; 40:150-62. | Article | PubMed

23. Olsson IN, Curman B and Engfeldt P. Patient focused drug surveillance of elderly patients in nursing homes. Pharmacoepidemiol Drug Saf. 2010; 19:150-7. | Article | PubMed

\section{Citation:}

Chaaban T, Ahouah M, Nasser W, Hijazi W, Lombrail P, Morvillers JM and Rothan-Tondeur M. Nurses' role in medical prescription: Systematic review. Journal of Nursing. 2018; 5:2.

http://www.hoajonline.com/nursing/2056-9157/5/2 